\title{
US Women's Perceptions and Acceptance of New Reproductive Health Technologies
}

\author{
Amber K. Worthington, ${ }^{1,2, *}$ Erin E. Burke, ${ }^{2}$ Talia N. Shirazi, ${ }^{2}$ and Carly Leahy ${ }^{2}$
}

\begin{abstract}
Background: Women have faced persistent problems accessing reproductive health care. New applications of health technologies to reproductive health, specifically online fertility specialist consultations and reproductive hormone self-collection tests (SCTs), present unique opportunities to overcome these issues. This article uses the technology acceptance model to examine factors that influence women's intentions to use these new reproductive health technologies.

Materials and Methods: Participants ( $n=327$ US women) completed an online survey assessing perceptions related to both of these reproductive health technologies, including usefulness, ease of use, risk, trust, subjective norms, and personal responsibility, to learn about fertility.

Results: Participants indicated high perceptions of usefulness, ease of use, and trust, as well as low perceptions of risk and subjective norms for both online fertility consultations (OFCs) and reproductive hormone SCTs. Women indicated low perceptions of responsibility to use OFCs, but high perceptions of responsibility to use reproductive hormone SCTs. Structural equation modeling indicated that intentions to use OFCs were predicted by usefulness, subjective norms, and responsibility; intentions to use reproductive hormone SCTs were predicted by usefulness, ease of use, subjective norms, and responsibility.

Conclusions: Fertility specialist consultations and reproductive hormone testing can provide women with essential fertility information that facilitates informed reproductive decisions; however, these services have historically been difficult to access. Widespread uptake of new reproductive health technologies could promote positive advances in women's reproductive health outcomes.
\end{abstract}

Keywords: fertility testing; online consultation; self-collection test; technology acceptance; telemedicine; reproductive hormones

\section{Introduction}

Recent trends show that women are delaying childbirth, and total fertility rates are decreasing. ${ }^{1,2}$ Women's access to reproductive health care services, including fertility specialists and reproductive hormone testing, is thus increasingly important. Indeed, fertility specialists have a greater understanding of fertility and can counsel women about natural age-related declines in fertility to help them realize their reproductive goals. ${ }^{3}$ Furthermore, reproductive hormone tests provide women with impor- tant information about their hormone levels, ovarian reserve, and fertility window ${ }^{4}$ and, again, can facilitate women's ability to achieve their reproductive goals. Past work has found that the information from reproductive hormone tests could lead women to alter their plans by, for example, trying to conceive children earlier or using fertility preservation technologies. ${ }^{5-7}$

Importantly, persistent problems have plagued women's access to these reproductive health care services. Many women face difficulties seeking care from

\footnotetext{
${ }^{1}$ Department of Communication, University of Alaska Anchorage, Anchorage, Alaska, USA.

${ }^{2}$ Modern Fertility, San Francisco, California, USA.

*Address correspondence to: Amber K. Worthington, PhD, Department of Communication, University of Alaska Anchorage, Anchorage, AK 99508, USA, E-mail: amber.kelly.worthington@gmail.com
}

(C) Amber K. Worthington et al., 2020; Published by Mary Ann Liebert, Inc. This Open Access article is distributed under the terms of the Creative Commons License (http://creativecommons.org/licenses/by/4.0), which permits unrestricted use, distribution, and reproduction in any medium, provided the original work is properly cited. 
a fertility specialist due to provider scarcity, geography, time, and cost. ${ }^{8,9}$ In the United States, there were only 463 fertility clinics reporting to the Centers for Disease Control and Prevention in 2016. ${ }^{10}$ Furthermore, even if women have access to a fertility specialist, infertility is a stigmatized condition, ${ }^{11,12}$ and women may feel uncomfortable seeking fertility health care from a specialist as people often delay or avoid seeking treatment for stigmatized conditions. ${ }^{13,14}$ Women have also faced difficulties accessing reproductive hormone testing due to cost, ${ }^{15,16}$ and women often lack the reproductive health education necessary to understand the importance of and results from these tests. ${ }^{17}$

New applications of health technologies have created an opportunity to overcome these barriers in accessing reproductive health care. Across sexual health care, there have been rapid increases in telemedicine ${ }^{18,19}$ and self-collection tests (SCTs) ${ }^{20,21}$ that have mitigated barriers to access, while still maintaining a high standard of patient treatment and satisfaction..$^{18,22,23}$ Within reproductive health care, it has recently become possible for women to seek care from fertility specialists through online fertility consultations (OFCs) and for women to use low-cost, reproductive hormone SCTs. ${ }^{4}$ As mentioned, the use of these tools can improve women's reproductive health outcomes. Thus, it is important to investigate factors that influence women to accept and use OFCs and reproductive hormone SCTs. The technology acceptance model (TAM) $)^{24,25}$ and extensions, including perceived risk and trust, ${ }^{26}$ subjective norms, ${ }^{27}$ and responsibility, ${ }^{28}$ are useful for understanding new technology acceptance. The goal of this study was thus to examine factors that influence women's acceptance of these new reproductive health technologies using the TAM. Figure 1 displays our theoretical models.

\section{TAM: perceived usefulness and perceived}

\section{ease of use}

The $\mathrm{TAM}^{24,25}$ examines factors that influence an individual's intended use of a particular technology. The TAM posits that intentions to accept and use a technology are directly influenced by perceived usefulness and perceived ease of use, and perceived usefulness is predicted by perceived ease of use. Perceived usefulness is defined as the degree to which an individual believes that using a particular technology would be beneficial, and both OFCs and reproductive hormone SCTs may be perceived as useful. Indeed, telemedicine allows health care providers to offer the same services they provide to patients during in-person consultations, ${ }^{18,19}$ and studies directly comparing phone- or video-based consultations to inperson health care consultations suggest similar patient outcomes and satisfaction. ${ }^{22,23}$ Together, this suggests that online consultations may be as useful as traditional in-person health care consultations. SCTs can be used interchangeably with venipuncture sampling to measure reproductive hormones, ${ }^{4}$ and a small-scale ethnographic study found that their participants believed the results from reproductive hormone SCTs were empowering. ${ }^{29}$ Again, this suggests that these reproductive SCTs may also be as useful as traditional reproductive hormone testing in in-person or laboratory settings.

Perceived ease of use is defined as the degree to which an individual believes that using a particular technology would be free from effort, and both OFCs and reproductive hormone SCTs may also be perceived as easy to use. Indeed, past research has found that both online consultations ${ }^{18,30}$ and SCTs ${ }^{21}$ for a wide range of health services circumvent the geographic, financial, and time-based limitations of in-person health care services. ${ }^{8,31}$ Both OFCs and reproductive hormone SCTs can also be used discreetly and in the privacy of one's own home, thus potentially mitigating some of the stigma felt by women pursuing fertility care. ${ }^{12}$ Both $\mathrm{OFCs}^{32}$ and reproductive hormone $\mathrm{SCTs}^{4}$ are commercially available; however, to date, there are no published studies of women's perceived usefulness and ease of use of these reproductive health technologies. In line with the TAM, we hypothesized the following:

\footnotetext{
$\mathrm{H} 1$ : Perceived usefulness is positively related to intentions to use (a) online fertility consultations and (b) reproductive hormone self-collection tests.

H2: Perceived ease of use is positively related to perceived usefulness of (a) online fertility consultations and (b) reproductive hormone self-collection tests.

H3: Perceived ease of use is positively related to intentions to use (a) online fertility consultations and (b) reproductive hormone self-collection tests.
}

\section{Perceived risk and trust}

Extensions of the TAM include perceived risk and trust as additional predictors of intentions to use a new technology. ${ }^{26}$ Perceived risk for health technology has been defined as the "degree of uncertainty related to use of the medium that is beyond the control of the information manager associated with the eHealth service." 19 Women may perceive OFCs as risky, as past research found that individuals who use telemedicine services for sexual health and medical abortions express concerns about privacy, confidentiality, and the risks associated with discussing and storing their personal health information online. ${ }^{19,33}$ Women may also perceive 


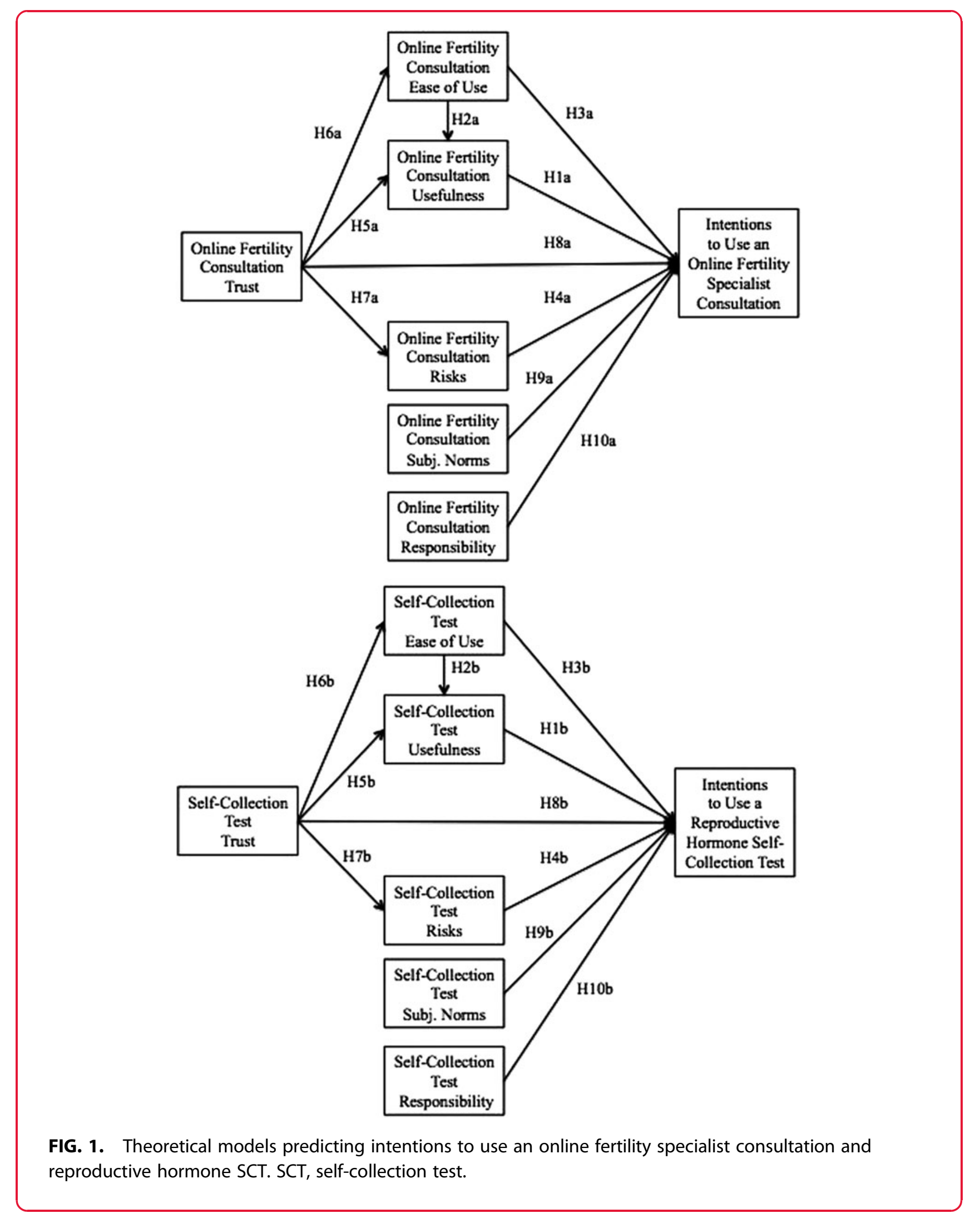


using reproductive hormone SCTs as risky, as past work has found that patients express concerns about privacy with self-collection genetic tests. ${ }^{34}$

Trust in health technology has been defined as "the belief that the other party will behave responsibly and will not attempt to exploit the vulnerabilities of the user," ${ }^{19}$ and a meta-analysis on the addition of trust to the TAM found strong relationships between trust and the major TAM variables (perceived ease of use, perceived usefulness, and behavioral intentions), suggesting that trust is important in the utilization of new technologies. ${ }^{35}$ Furthermore, trust improves an individual's beliefs about that online entity, which in turn attenuates perceptions of risk associated with using that online entity; thus, trust is posited to reduce perceptions of risk. ${ }^{25}$ Trust also likely plays a large role in use of reproductive health services, as reproductive health and infertility are fraught with stigma. ${ }^{12,36}$ Individuals may delay or avoid treatment to hide stigmatizing information from others, ${ }^{36,37}$ underscoring the importance of confidentiality for OFCs and reproductive hormone SCTs. We are not aware of any extant research on levels of risk and trust in these new reproductive health technologies. Using this extension of the TAM, we hypothesized the following:

H4: Perceived risk is negatively related to intentions to use (a) online fertility consultations and (b) reproductive hormone self-collection tests.

H5: Perceived trust is positively related to usefulness of (a) online fertility consultations and (b) reproductive hormone self-collection tests.

H6: Perceived trust is positively related to ease of use of (a) online fertility consultations and (b) reproductive hormone self-collection tests.

H7: Perceived trust is negatively related to perceived risk of (a) online fertility consultations and (b) reproductive hormone self-collection tests.

H8: Perceived trust is positively related to intentions to use (a) online fertility consultations and (b) reproductive hormone self-collection tests.

\section{Subjective norms}

Past work has shown that the TAM is a more useful model for predicting the acceptance of a new technology $^{25,38,39}$ than the theory of reasoned action (TRA) ${ }^{40}$ and the theory of planned behavior (TPB) ${ }^{39}$; however, integration of subjective norms from the TRA/TPB may be an important addition to the TAM (see the TAM $2^{41}$ ) and is supported by meta-analytic data. ${ }^{27}$ Subjective norms include an individual's beliefs about whether or not people important to them think they should perform the behavior. Women's use of fertility health care and, subsequently, new reproductive health technologies may be influenced by other people who are important to them, as reproductive decisionmaking often involves romantic partners ${ }^{42}$ and other family members. ${ }^{43,44}$ In line with this extension of the TAM, we thus hypothesized the following:

H9: Subjective norms are positively related to intentions to use (a) online fertility consultations and (b) reproductive hormone self-collection tests.

\section{Responsibility}

Perceptions of responsibility may be a key predictor of intentions to engage in health-related behaviors. ${ }^{28}$ Theoretical frameworks, including the Norm Activation Model, ${ }^{45}$ highlight the role of responsibility in predicting behavior. Likewise, meta-analyses have found that the inclusion of personal responsibility in the TPB explains an additional $3 \%-4 \%$ of the variation in intentions. ${ }^{46,47}$ Empirical work also suggests that perceptions of responsibility influence health-related behaviors, including obtaining a mammogram. ${ }^{48}$ To date, we are unaware of any research that has examined women's perceptions of responsibility to use OFCs and reproductive hormone SCTs or the role of responsibility in predicting technology acceptance. We thus propose an extension of the TAM to include responsibility with the following hypothesis:

H10: Responsibility is positively related to intentions to use (a) online fertility consultations and (b) reproductive hormone self-collection tests.

\section{Materials and Methods}

Participants were recruited through an electronic newsletter that was distributed through a national women's magazine in March 2019..$^{\dagger}$ Women who have voluntarily added themselves to this national women's magazine's email list received the recruitment message and survey link. No incentive was provided for participation. Eligible participants were 18-59 years of age, identified as women, and lived in the United States. After providing informed consent, an online questionnaire assessed participants' perceptions of usefulness, ease of use, trust, risk, subjective norms, personal responsibility to learn about fertility, and intentions to use for both OFCs and reproductive hormone SCTs. The study was approved by Western IRB, a third-party institutional review board accredited by the Association for the Accreditation of Human Research Protection Programs.

\section{Measures}

All variables were measured using 5-point Likert-type items. Each variable was measured for both OFCs and

'This magazine is not related to this study's funding source. 
reproductive hormone SCTs. Participants were asked to indicate the extent to which they agreed ("1" = "Strongly disagree" to " 5 " = "Strongly agree") with each statement. Scale descriptives are displayed in Table 2.

Perceived usefulness. Perceived usefulness was measured by two items ${ }^{19}$ : (1) I think a/n (online consultation with a fertility specialist/home fertility test) would be useful and (2) a/n (online consultation with a fertility specialist/home fertility test) would be beneficial.

Perceived ease of use. Perceived ease of use was measured by two items ${ }^{19}$ : (1) I think a/n (online consultation with a fertility specialist/home fertility test) would be easy to use and (2) it would be easy for me to learn how to use a/n (online consultation with a fertility specialist/home fertility test).

Perceived risk. Perceived risk for was measured by two items $^{26}$ : (1) I am concerned about using a/n (online consultation with a fertility specialist/home fertility test) because storing my health information online is risky and (2) I am concerned about using $\mathrm{a} / \mathrm{n}$ (online consultation with a fertility specialist/home fertility test) because storing my health information online is a threat to my privacy.

Perceived trust. Perceived trust was measured by two items $^{26}$ : (1) I trust that $\mathrm{a} / \mathrm{n}$ (online consultation with a fertility specialist/home fertility test) would keep my health information secure and (2) I am confident that I could trust in $\mathrm{a} / \mathrm{n}$ (online consultation with a fertility specialist/home fertility test).

Subjective norms. Subjective norms were measured by two items ${ }^{49}$ : (1) people who are important to me would think that I should use $\mathrm{a} / \mathrm{n}$ (online consultation with a fertility specialist/home fertility test) and (2) people whose opinions I value would think that I should use $\mathrm{a} / \mathrm{n}$ (online consultation with a fertility specialist/home fertility test).

Responsibility. Perceived responsibility to learn more about fertility was measured by two items ${ }^{28}$ : (1) I feel a personal responsibility to learn more about my hormones with $\mathrm{a} / \mathrm{n}$ (online consultation with a fertility specialist/home fertility test) and (2) learning more about my hormones with $\mathrm{a} / \mathrm{n}$ (online consultation with a fertility specialist/home fertility test) is my responsibility.

Intentions. Intentions to use were measured by two items ${ }^{50}$ : (1) I would buy a/n (online consultation with a fertility specialist/home fertility test) and (2) I intend to buy $\mathrm{a} / \mathrm{n}$ (online consultation with a fertility specialist/home fertility test).

\section{Data analysis}

To evaluate our hypotheses, we tested the theoretical models for OFCs and reproductive hormone SCTs (visualized in Fig. 1) by first analyzing both full measurement models. We then used a hybrid approach to test both structural models. ${ }^{51}$ We included one absolute fit statistic to test model fit, $\chi^{2},{ }^{51,52}$ and additional goodness-of-fit tests, including the comparative fit index (CFI) ${ }^{51,52}$ and the root mean squared error (RMSEA). ${ }^{53}$ AMOS 22.0 with maximum likelihood estimation was used for all measurement and structural analyses; $p \leq 0.05$ was set as the a priori significance level for hypothesis testing.

\section{Results}

A total of 327 women completed the survey. Participants ranged in age from 18 to 59 (mean $=34.11$, standard deviation $[\mathrm{SD}]=6.64)$. Participant demographics are displayed in Table 1 . The majority of women had completed a 4-year degree or graduate school (81.7\%) and self-identified as white $(75.8 \%)$ and heterosexual (95.1\%). One-third (33.33\%) of participants were previously diagnosed with or reported meeting diagnostic criteria for infertility. Means, standard deviations (SDs), and bivariate correlations between the theoretical variables are displayed in Table 2 and visualized in Figure 2. A series of one-sample $t$-tests were used to analyze the means of each scale against the midpoint (3) and revealed that women had high perceptions of usefulness, ease of use, and trust and low perceptions of risk and subjective norms for both OFCs and reproductive hormone SCTs. Women indicated low perceptions of responsibility to use OFCs, but high responsibility to use reproductive hormone SCTs. Women reported low intentions to use OFCs; intentions to use reproductive hormone SCTs did not differ from the midpoint.

The results of the structural equation modeling for OFCs are depicted in Figure 3 and Table 3. The power for testing the measurement model was excellent (0.99; with alpha $=0.05, d f=56, n=327$, null RMSEA $=$ 0.05 , and alt RMSEA $=0.08) .{ }^{54}$ The measurement model had adequate model fit $\left(\chi^{2}(56, n=327)=175.18\right.$, $p<0.001$; CFI $=0.97$; RMSEA $=0.081,90 \%$ confidence interval (CI) $(0.067,0.094), p$-close $<0.01)$. The power for testing the structural model was excellent (0.99; with alpha $=0.05, d f=64, n=327$, null RMSEA $=$ 0.05 , and alt RMSEA $=0.08) .{ }^{54}$ The structural model 
Table 1. Participant Demographics

\begin{tabular}{|c|c|c|}
\hline & $n$ & $\%$ \\
\hline \multicolumn{3}{|l|}{ Education } \\
\hline Less than high school & 1 & 0.30 \\
\hline High school graduate & 6 & 1.83 \\
\hline Some college & 39 & 11.92 \\
\hline 2-year degree & 14 & 4.28 \\
\hline 4-year degree & 136 & 41.59 \\
\hline Attended and/or completed graduate school & 131 & 40.06 \\
\hline \multicolumn{3}{|c|}{ Racial/ethnic background (note: could select more than one) } \\
\hline American Indian or Alaskan & 2 & 0.61 \\
\hline Asian & 18 & 5.50 \\
\hline Black or African American & 28 & 8.56 \\
\hline Native Hawaiian or other Pacific Islander & 3 & 0.92 \\
\hline White & 248 & 75.84 \\
\hline Hispanic or Latino & 44 & 13.46 \\
\hline Other & 6 & 1.83 \\
\hline Prefer not to say & 3 & 0.92 \\
\hline \multicolumn{3}{|l|}{ Sexual orientation } \\
\hline Heterosexual or straight & 311 & 95.11 \\
\hline Gay or lesbian & 1 & 0.30 \\
\hline Bisexual & 15 & 4.58 \\
\hline \multicolumn{3}{|l|}{ Relationship status } \\
\hline Single (never married) & 55 & 16.82 \\
\hline In a monogamous, dating relationship & 45 & 13.76 \\
\hline In an open, dating relationship & 1 & 0.30 \\
\hline In a domestic partnership or living with a partner & 35 & 10.70 \\
\hline Married & 184 & 56.27 \\
\hline Widowed & 0 & 0 \\
\hline Divorced & 6 & 1.83 \\
\hline Separated & 1 & 0.30 \\
\hline \multicolumn{3}{|l|}{ Geographic region } \\
\hline Northeast & 62 & 18.96 \\
\hline Midwest & 60 & 18.34 \\
\hline South & 101 & 30.89 \\
\hline West & 97 & 29.66 \\
\hline Pacific & 0 & 0 \\
\hline Did not indicate & 5 & 1.53 \\
\hline \multicolumn{3}{|l|}{ Fertility status } \\
\hline Fertile & 218 & 66.66 \\
\hline Infertile & 109 & 33.33 \\
\hline
\end{tabular}

had adequate model fit $\left(\chi^{2}(64, n=327)=234.86\right.$, $p<0.001$; CFI $=0.96$; RMSEA $=0.090,90 \%$ CI $(0.078$, $0.103)$, $p$-close $<0.01)$. Seven of the 10 hypothesized direct paths were statistically significant.

The results of the structural equation modeling for reproductive hormone SCTs are depicted in Figure 3 and Table 3. The power for testing the measurement model was excellent $(0.99$; with alpha $=0.05, d f=56$, $n=327$, null RMSEA $=0.05$, and alt RMSEA $=0.08) .{ }^{54}$ The measurement model has good model fit $\left(\chi^{2}(56\right.$, $n=327)=114.91, p<0.001 ; \mathrm{CFI}=0.98$; RMSEA $=0.057$, $90 \%$ CI $(0.042,0.072), p$-close $=0.21)$. The power for testing the structural model was excellent (0.99; with alpha $=0.05, d f=64, n=327$, null RMSEA $=0.05$, and alt RMSEA $=0.08){ }^{54}$ The structural model had good model fit $\left(\chi^{2}(64, n=327)=140.88, p<0.001 ; \mathrm{CFI}=0.98\right.$; RMSEA $=0.061,90 \%$ CI $(0.047,0.074), p$-close $=0.09)$. Seven of the 10 hypothesized direct paths were statistically significant.

In summary, women's intentions to use OFCs were significantly predicted by perceptions of responsibility to learn about their fertility with OFCs, beliefs that other people important to them think they ought to use OFCs, and perceptions that OFCs are useful. Women's intentions to use reproductive hormone SCTs were significantly predicted by perceptions of responsibility to learn about their fertility with reproductive hormone SCTs, beliefs that other people important to them think they ought to use reproductive hormone SCTs, and perceptions that reproductive hormone SCTs are useful and easy to use.

\section{Discussion}

Women have historically faced many difficulties accessing reproductive health care services, including fertility

Table 2. Means, Standard Deviations, and Bivariate Correlations of Theoretical Variables

\begin{tabular}{|c|c|c|c|c|c|c|c|c|c|c|}
\hline & 1 & 2 & 3 & 4 & 5 & 6 & 7 & Mean & SD & $\alpha$ \\
\hline OFC usefulness & - & & & & & & & 3.66 & 0.89 & 0.96 \\
\hline OFC ease of use & $0.65^{*}$ & - & & & & & & 3.78 & 0.77 & 0.86 \\
\hline OFC risks & $-0.19^{*}$ & $-0.21^{*}$ & - & & & & & 2.78 & 0.99 & 0.94 \\
\hline OFC trust & $0.60^{*}$ & $0.60^{*}$ & $-0.49^{*}$ & - & & & & 3.47 & 0.83 & 0.85 \\
\hline OFC subjective norms & $0.46^{*}$ & $0.33^{*}$ & $-0.16^{*}$ & $0.47^{*}$ & - & & & 2.67 & 0.91 & 0.97 \\
\hline OFC responsibility & $0.50^{*}$ & $0.41^{*}$ & $-0.10^{*}$ & $0.47^{*}$ & $0.65^{*}$ & - & & 2.88 & 0.99 & 0.86 \\
\hline OFC intentions & $0.58^{*}$ & $0.44^{*}$ & $-0.22^{*}$ & $0.49^{*}$ & $0.59^{*}$ & $0.60^{*}$ & - & 2.81 & 1.02 & 0.80 \\
\hline SCT usefulness & - & & & & & & & 4.03 & 0.83 & 0.93 \\
\hline SCT ease of use & $0.45^{*}$ & - & & & & & & 3.92 & 0.77 & 0.80 \\
\hline SCT risks & $-0.22^{*}$ & $-0.19^{*}$ & - & & & & & 2.86 & 1.02 & 0.89 \\
\hline SCT trust & $0.59^{*}$ & $0.55^{*}$ & $-0.36^{*}$ & - & & & & 3.51 & 0.87 & 0.80 \\
\hline SCT subjective norms & $0.35^{*}$ & $0.30^{*}$ & $-0.12^{*}$ & $0.34^{*}$ & - & & & 2.85 & 0.96 & 0.96 \\
\hline $\mathrm{SCT}$ responsibility & $0.51^{*}$ & $0.34^{*}$ & $-0.12^{*}$ & $0.46^{*}$ & $0.54^{*}$ & - & & 3.28 & 1.05 & 0.82 \\
\hline SCT intentions & $0.58^{*}$ & $0.43^{*}$ & $-0.16^{*}$ & $0.46^{*}$ & $0.53^{*}$ & $0.67^{*}$ & - & 3.09 & 1.05 & 0.84 \\
\hline
\end{tabular}

${ }^{*} p<0.05$.

OFC, online fertility consultation; SCT, self-collection test; SD, standard deviation. 


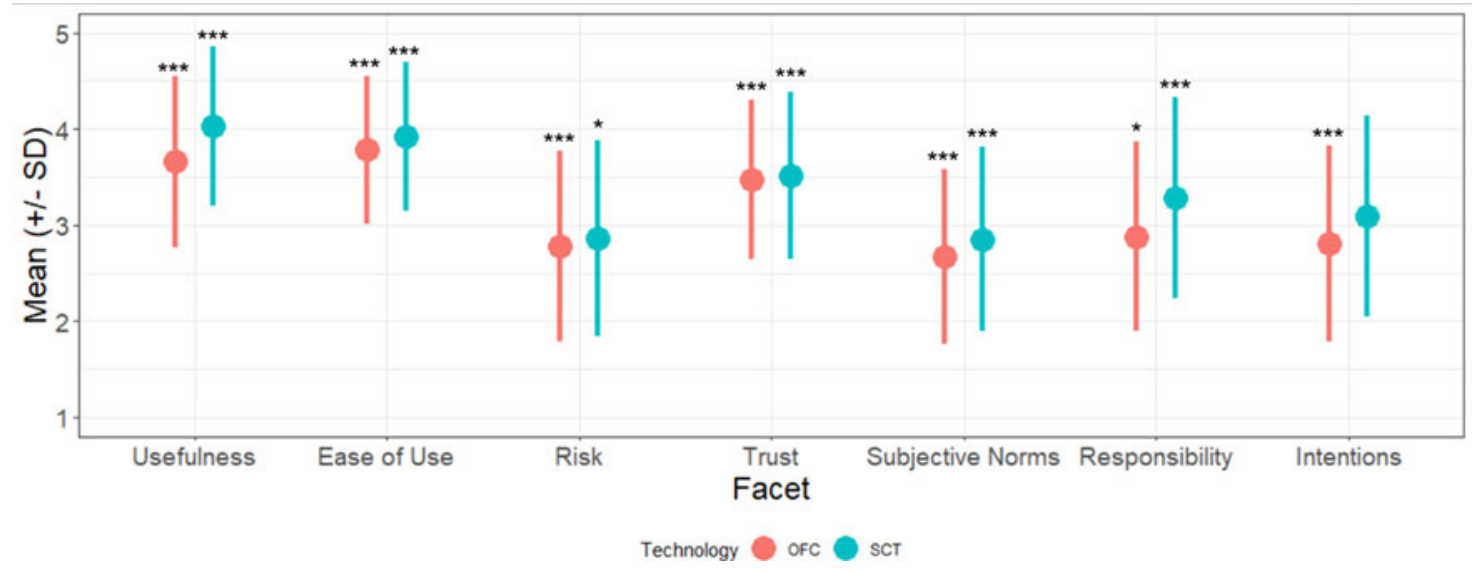

FIG. 2. Women's perceptions of online fertility consultations and reproductive hormone SCTs. Note: Asterisks indicate a statistically significant difference $\left({ }^{*} p<0.05,{ }^{* * *} p<0.001\right)$ from the scale midpoint.

specialists and reproductive hormone testing. ${ }^{8,9,16,17}$ The coronavirus disease 2019 (COVID-19) pandemic will also likely exacerbate women's access to sexual and reproductive care. ${ }^{55}$ OFCs and reproductive hormone SCTs ${ }^{4}$ can help overcome these barriers and enable women to gain critical fertility information. The goal of this article was therefore to examine women's perceptions of OFCs and reproductive hormone SCTs and factors that influence women's intentions to use these new reproductive health technologies. Our results support our overall extension of the TAM to include perceived risk, trust, subjective norms, and responsibility.

Perceptions of responsibility were the largest predictor of intentions to use both OFCs and reproductive hormone SCTs. These findings suggest that perceptions of responsibility play an important role in the acceptance of new reproductive health technologies and thus support our theoretical extension of the TAM. Practically speaking, these results suggest that women would be more likely to utilize OFCs and reproductive hormone SCTs, and thus gain the benefits from doing so through heightened perceptions that learning about their fertility is their responsibility. Importantly, however, women have historically been burdened with a disproportionate amount of responsibility for reproductive health care ${ }^{56}$ and past work has found that perceptions of responsibility for health can unintentionally lead to guilt, shame, or frustration when an individual is not able to adopt a recommended practice. ${ }^{57}$ Furthermore, responsibility may be central to the formation of stigma beliefs, ${ }^{58}$ and reproductive health ${ }^{36}$ and infertility $^{12}$ are already stigmatized. Together, this suggests that caution should be taken when considering increasing perceptions of responsibility to motivate the acceptance and use of OFCs and reproductive hormone SCTs. Perceptions of subjective norms and usefulness, which were also significant predictors of intentions to use both reproductive health technologies, should thus be considered.

Subjective norms predicted intention to use both OFCs and reproductive hormone SCTs, indicating that women's beliefs that other people who are important to them think they ought to use these new reproductive health technologies play an important role in women's acceptance and intentions to do so. These results support previous extensions of the TAM that include subjective norms. ${ }^{27,41}$ These results also suggest that reproductive decisions are not solely a function of women alone, but instead include important others such as romantic partners, family members, or health care providers, which aligns with previous work. ${ }^{42}$ It is possible to increase these beliefs by encouraging women who have already used these technologies to share their experiences with their friends. For example, women who received a medical abortion through telemedicine were more likely to recommend the service to a friend than those who saw a physician in person. ${ }^{30}$ Women may be further motivated to use these new reproductive health technologies if health care providers also suggest they do.

Perceptions of usefulness also predicted intentions to use both OFCs and reproductive hormone SCTs, which 

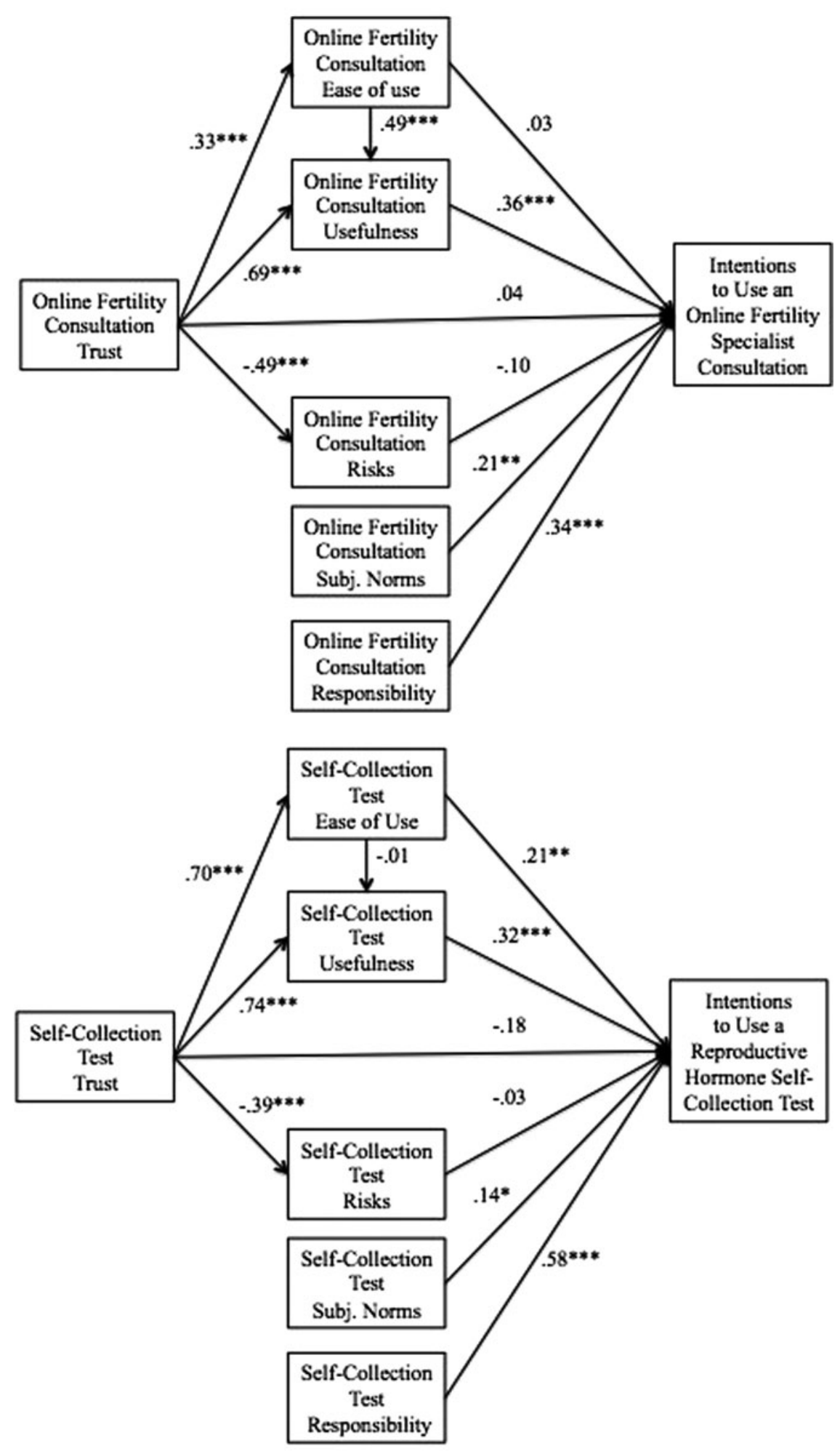

FIG. 3. Structural equation modeling results predicting intentions to use an online fertility specialist consultation and reproductive hormone SCT. ${ }^{*} p<0.05,{ }^{* *} p<0.01,{ }^{* * *} p<0.001$. 
Table 3. Structural Equation Model Results

\begin{tabular}{lrrr}
\hline & $\beta$ & $B$ & SE \\
\hline OFCs & & & \\
H1a, OFCs usefulness $\rightarrow$ intentions to use & $0.36^{* * *}$ & 0.31 & 0.06 \\
H2a, OFCs ease of use $\rightarrow$ intentions to use & 0.03 & 0.03 & 0.08 \\
H3a, OFCs ease of use $\rightarrow$ usefulness & $0.49^{* * *}$ & 0.59 & 0.08 \\
H4a, OFCs risk $\rightarrow$ intentions to use & -0.10 & -0.07 & 0.04 \\
H5a, OFCs trust $\rightarrow$ usefulness & $0.33^{* * *}$ & 0.38 & 0.08 \\
H6a, OFCs trust $\rightarrow$ ease of use & $0.69^{* * *}$ & 0.65 & 0.05 \\
H7a, OFCs trust $\rightarrow$ risk & $-0.49^{* * *}$ & -0.65 & 0.07 \\
H8a, OFCs trust $\rightarrow$ intentions to use & 0.04 & 0.04 & 0.09 \\
H9a, OFCs subj. norms $\rightarrow$ intentions to use & $0.21^{* *}$ & 0.18 & 0.06 \\
H10a, OFCs responsibility $\rightarrow$ intentions & $0.34^{* * *}$ & 0.29 & 0.06 \\
to use & & & \\
Reproductive hormone SCTs & & & \\
H1b, SCTs usefulness $\rightarrow$ intentions to use & $0.32^{* * *}$ & 0.34 & 0.08 \\
H2b, SCTs ease of use $\rightarrow$ intentions to use & $0.21^{* *}$ & 0.30 & 0.11 \\
H3b, SCTs ease of use $\rightarrow$ usefulness & -0.01 & -0.02 & 0.12 \\
H4b, SCTs risk $\rightarrow$ intentions to use & -0.03 & -0.03 & 0.04 \\
H5b, SCTs trust $\rightarrow$ usefulness & $0.74^{* * *}$ & 0.80 & 0.10 \\
H6b, SCTs trust $\rightarrow$ ease of use & $0.70^{* * *}$ & 0.56 & 0.06 \\
H7b, SCTs trust $\rightarrow$ risk & $-0.39^{* * *}$ & -0.53 & 0.08 \\
H8b, SCTs trust $\rightarrow$ intentions to use & -0.18 & -0.21 & 0.14 \\
H9b, SCTs subj. norms $\rightarrow$ intentions to use & $0.14^{*}$ & 0.13 & 0.05 \\
H10b, SCTs responsibility $\rightarrow$ intentions to use & $0.58^{* * *}$ & 0.62 & 0.08 \\
\hline
\end{tabular}

${ }^{*} p<.05,{ }^{* *} p<.01,{ }^{* * *} p<.001$.

$\mathrm{SE}$, standard error.

indicates that women's intentions to use these new reproductive technologies are related to their belief that doing so is beneficial. Past research suggests that both online consultations ${ }^{22,23}$ and reproductive hormone SCTs ${ }^{4}$ are as useful as traditional in-person consultations and venipuncture sampling. Our results suggest that women do recognize these benefits, as they perceived both OFCs and reproductive hormone SCTs as useful. Health care providers or public health campaigns could increase the use of OFCs and reproductive hormone SCTs by emphasizing that, in this era of delayed childbirth, ${ }^{1}$ these reproductive health technologies may facilitate informed decisions that might aid women in achieving their reproductive goals.

Ease of use was a significant predictor of intentions to use reproductive hormone SCTs, but not intentions to use OFCs. Both video-chat applications and online health care consultations have been steadily increasing. ${ }^{59}$ Thus, the ease with which many people engage in these technologies may modulate the influence of perceptions of ease of use on the acceptance of OFCs. SCTs, however, are less common as, to date, only four companies offer this testing. ${ }^{60,61}$ Most reproductive hormone SCTs require a fingerstick method to collect a blood sample; thus, women's intentions to use this technology is justifiably influenced by their perceptions of their ability to do so.
Interestingly, our study found that perceptions of risk and trust do not predict intentions to use OFCs or reproductive hormone SCTs, and, overall, perceptions of risk were low and perceptions of trust were high for both technologies. These results are surprising, as previous research notes that patients have concerns about privacy and risks associated with storing their personal health information online with telemedicine services ${ }^{19,33}$ and with SCTs. ${ }^{34}$ Likewise, the stigma in reproductive health ${ }^{12,36}$ underscores the need for patients to trust in fertility health care services. However, past work has also noted that online consultations may be more readily accepted if patients are provided with clear and accessible privacy policies. ${ }^{33}$ Furthermore, with the increasing use of the Internet for these services, ${ }^{59}$ this information may already be more readily available, and patients may be more accustomed to using technology in this way. ${ }^{59}$

Importantly, OFCs and reproductive hormone SCTs may be most beneficial in promoting positive reproductive health and fertility outcomes when used together. Indeed, OFCs may be particularly beneficial as a way to help women understand their results from reproductive hormone $\mathrm{SCTs}^{62}$ or as psychological counseling sessions after unexpected or undesired results. For example, a recent small-scale ethnographic study found that their participants believed the reproductive hormone SCTs could be empowering; however, some participants were uncertain about how to interpret the test results and the appropriate next steps to take. ${ }^{29}$ Pairing a reproductive hormone SCT with an online fertility specialist consultation could thus improve patient experience and ability to use the reproductive hormone SCT results effectively.

Finally, as mentioned, the COVID-19 pandemic may result in additional barriers for women to access reproductive health care services. ${ }^{55}$ For example, reproductive health providers and clinics may be deemed "nonessential" and redirected to respond to COVID19 . $^{63}$ Thus, telemedicine services may be ideal for limiting the number of patients within a given hospital or clinic and preventing unnecessary human exposures, while still promoting high-quality health care. ${ }^{64}$ Together, this underscores the increasing importance of providing online reproductive health services, including OFCs and reproductive hormone-SCTs. Promoting intentions to use these online services has therefore become increasingly important and relevant.

\section{Limitations and future directions}

This is the first study that directly examines women's perceptions of OFCs and reproductive hormone SCTs 
and applies the TAM and its extensions to examine women's intentions to utilize these new reproductive health technologies. However, this sample was homogenous with respect to age, education, sexual orientation, and race. Prior work has shown that demographic factors, particularly age, ${ }^{65}$ may modulate telemedicine utilization; as such, future research should examine perceptions of fertility-related telemedicine services in more diverse samples. We were not able to test the effect of certain factors related to reproductive health status, like current pregnancy status, on perceptions of fertility-related telemedicine services. Thus, future work should make sure to examine such factors. We also analyzed predictors of women's intentions to use OFCs and hormone SCTs, rather than predictors of women's actual use of these technologies. As these services become increasingly available and widespread in use, future work should examine women's actual utilization of OFCs and reproductive hormone SCTs. Finally, we used two items to measure each theoretical construct in our extension of the TAM. The measurement models for both OFCs and reproductive hormone SCTs had adequate model fit; however, future work should measure each variable with additional items.

\section{Conclusions}

As age of first childbirth is delayed ${ }^{1}$ and total fertility rates decrease, ${ }^{2}$ it is particularly important to provide women with access to reproductive health care services that facilitate their ability to make informed reproductive decisions. Online consultations with fertility specialists and reproductive hormone SCTs present new and unique opportunities to overcome the barriers women have historically faced accessing these services. To promote the use of these new reproductive health technologies, health campaigns should originate from important others (such as physicians) and should emphasize that these technologies are useful and easy to use. It is our hope that widespread utilization of these reproductive health technologies can aid in reducing the number of women who suffer from infertility by increasing awareness and treatment.

\section{Author Disclosure Statement}

The study was sponsored by Modern Fertility, a women's health company focused on making fertility information accessible earlier in life by offering commercial testing of fertility hormones and education resources. All authors worked on the study in the capacity of paid consultants or employees of Modern Fertility.

\section{Funding Information}

This research was funded by Modern Fertility, San Francisco, California, USA.

\section{References}

1. Ely DM, Hamilton BE. Trends in fertility and mother's age at first birth among rural and metropolitan counties: United States, 2007 - 2017. NCHS Data Brief 2018;323:1-8.

2. Mathews TJ, Hamilton BE. Mean age of mothers is on the rise: United States, 2000-2014. NCHS Data Brief 2016;232:1-8.

3. Miller EJN, Cookingham LM, Woodruff TK, et al. Fertility preservation training for obstetrics and gynecology fellows: A highly desired but non-standardized experience. Fertil Res Pract 2017;3:1-6.

4. Burke EE, Beqaj S, Douglas NC, Luo R. Concordance of fingerstick and venipuncture sampling for fertility hormones. Obstet Gynecol 2019;133: 343-348.

5. Azhar E, Seifer DB, Melzer K, Ahmed A, Weedon J, Minkoff H. Knowledge of ovarian reserve and reproductive choices. J Assist Reprod Genet 2015; 43:409-415.

6. Bavan B, Porzig E, Baker VL. An assessment of female university students' attitudes toward screening technologies for ovarian reserve. Fertil Steril 2011;96:1195-1199.

7. Clark N, Griffith K, Perkins E, Jagsi R. Experiences with fertility and infertility among generation X physicians. Fertil Steril 2013;100:S317.

8. Missmer SA, Seifer DB, Jain T. Cultural factors contributing to health care disparities among patients with infertility in Midwestern United. Fertil Steril 2011;95:1943-1949.

9. Ethics Committee of the American Society of Reproductive Medicine. Disparities in access to effective treatment for infertility in the United States: an Ethics Committee opinion. Fertil Steril 2015;104:1104-1110.

10. Sunderam S, Kissin DM, Crawford SB, et al. Assisted reproductive technology surveillance-United States, 2015. Morb Mortal Wkly Rep 2018;67:1-28.

11. Miall CE. Community constructs of involuntary childlessness: Sympathy, stigma, and social support. Can Rev Sociol 1994;31:392-421.

12. Worthington AK, Burke EE, Leahy CA. A comprehensive examination of infertility stigma among fertile and infertile women in the United States. Fertil Steril 2019;112:e378.

13. Sternke EA, Abrahamson K. Perceptions of women with infertility on stigma and disability. Sex Disabil 2015;33:3-17.

14. Slade $P$, Neill CO, Simpson AJ, Lashen $H$. The relationship between perceived stigma, disclosure patterns, support and distress in new attendees at an infertility clinic. Hum Reprod 2007;22:2309-2317.

15. Kelley AS, Qin Y, Marsh EE, Dupree JM. Disparities in accessing infertility care in the United States: Results from the National Health and Nutrition Examination Survey, 2013-2016. Fertil Steril 2019;112:562-568.

16. Henne MB, Bundorf MK, Ph D. Insurance mandates and trends in infertility treatments. Fertil Steril 2008;89:66-73.

17. Brien AYO, Martyn F, Glover LE, Wing MB. What women want? A scoping survey on women's knowledge, attitudes and behaviours toward ovarian reserve testing and egg freezing. Eur J Obstet Gynecol Reprod Biol 2017; 217:71-76

18. Kohn JE, Snow JL, Simons HR, Seymour JW, Thompson T, Grossman D. Medication abortion provided through telemedicine in four U.S. states. Obstet Gynecol 2019;134:343-350.

19. Schnall R, Bakken S, Rojas M, Travers J, Carballo-Dieguez A. mHealth technology as a persuasive tool for treatment, care and management of persons living with HIV. AIDS Behav 2015;19:81-89.

20. Huynh J, Howard M, Lytwyn A. Self-collection for vaginal human papillomavirus testing: Systematic review of studies asking women their perceptions. J Low Genit Tract Dis 2010;14:356-362.

21. Hebl SS, Livingston JB, Merchant M, Postlewaite DA. Perceptions and acceptability of self-testing for human papillomavirus among women presenting for cervical cancer screening. Obstet Gynecol 2015;125:S19-S20.

22. Coelho JJ, Arnold A, Nayler J, Tischkowitz M, Mackay J. An assessment of the efficacy of cancer genetic counselling using real-time videoconferencing technology (telemedicine) compared to face-to-face consultations. Eur J Cancer 2005;41:2257-2261.

23. Mitchell JE, Crosby RD, Wonderlich SA, et al. A randomized trial comparing the efficacy of cognitive-behavioral therapy for bulimia nervosa delivered via telemedicine versus face-to-face. Behav Res Ther 2008;46:581-592. 
24. Davis FD. Perceived usefulness, perceived ease of use, and user acceptance of information. MIS Q 1989;13:319-340.

25. Davis FD, Bagozzi R. User acceptance of computer technology: A comparison of two theoretical models. Manage Sci 1989;35:982-1003.

26. Pavlou PA. Consumer acceptance of electronic commerce: Integrating trust and risk with the technology acceptance model. Int J Electron Commer 2003;7:101-134.

27. Schepers J, Wetzels M. A meta-analysis of the technology acceptance model: Investigating subjective norm and moderation effects. Inf Manag 2007;44:90-103.

28. Worthington AK. Responsibility in health and risk messaging. In: Parrott $R$ (ed.). Oxford research encyclopedia of communication. Oxford, United Kingdom: Oxford University Press, 2017.

29. Kyweluk MA. Quantifying fertility? Direct-to-consumer ovarian reserve testing and the new (in)fertility pipeline. Soc Sci Med 2020;245:112697.

30. Grossman D, Grindlay K, Buchacker T, Lane K, Blanchard K. Effectiveness and acceptability of medical abortion provided through telemedicine. Obstet Gynecol 2011;118:296-303.

31. Hjelm NM. Benefits and drawbacks of telemedicine. J Telemed Telecare 2005;11:60-70.

32. Center for Advanced Reproductive Services. Free Fertility Consultation, 2020. Available at: https://www.uconnfertility.com/treatments-services/ free-fertility-consultation/ Accessed March 2, 2020.

33. Garrett CC, Hocking J, Chen MY, Fairley CK, Kirkman M. Young people's views on the potential use of telemedicine consultations for sexual health: Results of a national survey. BMC Infect Dis 2011;11:285.

34. Critchley C, Nicol D, Otlowski M, Chalmers D. Public reaction to direct-toconsumer online genetic tests: Comparing attitudes, trust and intentions across commercial and conventional providers. Public Underst Sci 2015 24:731-750.

35. Wu K, Zhao $\mathrm{Y}$, Zhu Q, Tan X, Zheng H. A meta-analysis of the impact of trust on technology acceptance model: Investigation of moderating influence of subject and context type. Int J Inf Manage 2011;31:572-581.

36. Cook RJ, Dickens BM. Reducing stigma in reproductive health. Int J Gynecol Obstet 2014;125:89-92.

37. Link BG, Phelan JC. Conceptualizing stigma. Annu Rev Sociol 2001;27: 363-385.

38. Mathieson K. Predicting user intentions: Comparing the technology acceptance model with the theory of planned behavior. Inf Syst Res 1991;2: 173-191.

39. Chau PYK, Hu PJ. Investigating health care professionals' decisions to accept telemedicine technology: An empirical test of competing theories. Inf Manag 2002;39:297-311.

40. Ajzen I, Fishbein M. Understanding attitudes and predicting social behavior. Englewood Cliffs, NJ: Prentice Hall, 1980.

41. Legris $P$, Ingham J, Collerette P. Why do people use information technology? A critical review of the technology acceptance model. Inf Manag 2003;40:191-204.

42. Stein $P$, Willen $S$, Pavetic M. Couples' fertility decision-making. Demogr Res 2014:30:1697-1732.

43. Bernardi L, Klärner A. Social networks and fertility. Demogr Res 2014;30: 641-670.

44. Barber JS, Axinn WG. The impact of parental pressure for grandchildren on young people's entry into cohabitation and marriage. Popul Stud (NY) 1998;52:129-144.

45. Schwartz SH. Normative influence on altruism. In: Berkowitz L, ed. Advances in experimental social psychology. New York: Academic Press, 1977:221-279.

46. Rivis A, Sheeran P, Armitage C. Expanding the affective and normative components of the theory of planned behavior: A meta-analysis of an ticipated affect and moral norms. J Appl Soc Psychol 2009;39:29853019.

47. Conner M, Armitage J. Extending the theory of planned behavior: A review and avenues for further research. J Appl Soc Psychol 1998;28:14291464.

48. Rothman AJ, Salovey P, Turvey C, Fishkin SA. Attributions of responsibility and persuasion: Increasing mammography utilization among women over 40 with an internally oriented message. Heal Psychol 1993;12:39-47.

49. Parker HS, Smith SW. Distinctiveness and influence of subjective norms, personal descriptive and injuctive norms, and societal descriptive and injunctive norms on behavioral intent: A case of two behaviors critical to organ donation. Hum Commun Res 2007;33:194-218.
50. Azjen I. Constructing a theory of planned behavior questionnaire, 2006 Available at: https://people.umass.edu/aizen/pdf/tpb.measurement.pdf Accessed March 1, 2020.

51. Holbert RL, Stephenson MT. Structural equation modeling in the communication sciences, 1995-2000. Hum Commun Res 2002;28:531-551.

52. Hu L, Bentler PM. Cutoff criteria for fit indexes in covariance structure analysis: Conventional criteria versus new alternatives. Struct Equ Model 1999;6:1-55.

53. Browne MW, Cudeck R. Alternative ways of assessing model fit. In: Bollen K, Long JS, eds. Testing structural equation models. Newbury Park, CA: Sage Publications, 1993:136-162.

54. Preacher KJ, Coffman DL. Computing power and minimum sample size for RMSEA [Computer software], 2006. Available at: http://www.quantpsy .org/rmsea/rmsea.htm Accessed March 1, 2020

55. Stidham Hall K, Samari G, Garbers S, et al. Centring sexual and reproductive health and justice in the global COVID-19 response. Lancet 2020; 395:1175-1177.

56. Robbins CL, Gavin L, Zapata LB, Marion W, Lachance C, Mautone-Smith N. Preconception care in publicly funded US clinics that provide family planning services. Am J Prev Med 2016:51:336-343.

57. Guttman N, Salmon CT. Guilt, fear, stigma and knowledge gaps: Ethical issues in public health communication interventions. Bioethics 2004;18: 531-552.

58. Smith RA. Language of the lost: An explication of stigma communication. Commun Theory 2007;17:462-485.

59. FAIR Health. FH Healthcare indicators and FH medical price index 2019 An annual review of place of service trends and medical pricing. 2019. Available at: https://s3.amazonaws.com/media2.fairhealth.org/ whitepaper/asset/FH. Healthcare Indicators and FH Medical Price Index 2019 - A FAIR Health White Paper.pdf Accessed March 1, 2020.

60. Everlywell, 2019. Available at: https://www.everlywell.com/ Accessed September 12, 2019.

61. Modern Fertility, 2019. Available at: https://modernfertility.com/ Accessed September 9, 2020

62. Worthington AK, Parrott RL, Smith RA, Worthington AK, Parrott RL, Smith RA. Spirituality, illness unpredictability, and math anxiety effects on negative affect and affect-management coping for individuals diagnosed with alpha-1 antitrypsin deficiency. Health Commun 2018;33:363-371.

63. United Nations Population Fund. COVID-19: A gender lens protecting sexual and reproductive health and rights and promoting gender equality, 2020. Available at: https://www.unfpa.org/sites/default/files/ resource-pdf/COVID-19_A_Gender_Lens_Guidance_Note.pdf Accessed March 1, 2020.

64. Rockwell KL, Gilroy AS. Incorporating telemedicine as part of COVID-19 outbreak response systems. Am J Manag Care 2020;26:147-148.

65. Uscher-Pines L, Mehrotra A. Analysis of teladoc use seems to indicate expanded access to care for patients without prior connection to a provider. Health Aff 2014;33:258-264.

Cite this article as: Worthington AK, Burke EE, Shirazi TN, Leahy C (2020) US women's perceptions and acceptance of new reproductive health technologies, Women's Health Reports 1:1, 402-412, DOI: 10.1089/whr.2020.0063

$$
\begin{aligned}
& \text { Abbreviations Used } \\
& \mathrm{CFI}=\text { comparative fit index } \\
& \mathrm{CI}=\text { confidence interval } \\
& \text { COVID-19 }=\text { coronavirus disease } 2019 \\
& \mathrm{OFC}=\text { online fertility consultation } \\
& \text { RMSEA }=\text { root mean squared error } \\
& \mathrm{SCT}=\text { self-collection test } \\
& \mathrm{SD}=\text { standard deviation } \\
& \mathrm{SE}=\text { standard error } \\
& \text { TAM }=\text { technology acceptance model } \\
& \text { TPB }=\text { theory of planned behavior } \\
& \text { TRA }=\text { theory of reasoned action }
\end{aligned}
$$

